\title{
The stability of benthic ecosystems
}

\author{
J.S. GraY \\ Institutt for Marin Biologi, Universitetet i Oslo; \\ Blindern, Oslo 3, Norway, \\ and \\ Wellcome Marine Laboratory, University of Leeds; \\ Robin Hood's Bay, N. Yorksbire, Great Britain
}

\begin{abstract}
Physicists have two conceptions of the stability of systems: global and neighbourhood stability. Global stability corresponds to the idea of successional changes leading to climax communities. Yet, neighbourhood stability is shown to be a more realistic model for changes in dominance of marine benthic sediment-living communities. The factors inducing state changes in dominance pattern were shown to be principally biological interactions. In order to model the stability of benthic ecosystems, much more attention must be given to natural history-type studies of biological interactions. Furthermore, mathematical models usually assume that the systems are globally stable. Should neighbourhood stability prove to be the rule for benchic systems then realistic models of such systems will be an order of magnitude more complex.
\end{abstract}

\section{INTRODUCTION}

Mathematically the simplest and most tractable form of stability analysis is that concerned with neighbourhood stability (Lewontin, 1969; May, 1973). A system is considered in neighbourhood stability if after a small perturbation the system returns to an equilibrium point. If all the points within a vector field are directed towards a stable equilibrium point, then the area enclosing the points is known as a basin of attraction. Many ecological applications of neighbourhood stability can be envisaged. For example when the presence of a predator reduces the numbers of a population, but on removal of the predator the population returns to an equilibrium level, then that population shows neighbourhood stability. Similarly at a community level, perturbation by the presence of a predator or by a change in the substratum may alter dominance patterns of a set of species. If removal of the predator or a return to the original substratum conditions results in a return to the equilibrium dominance pattern then that community can be said to exhibit neighbourhood stability. The basin of attraction in the above examples will be the maximum fluctuation from which the population or set of species can return to the equilibrium level.

An equilibrium point within a vector field of neighbourhood stability may be in either unstable (Fig. 1i) or stable equilibrium (Fig. 1ii). In Figure 1i a very small 
perturbation (1) will result in the system returning to its equilibrium point, but a larger perturbation (2) will carry the system to another basin of attraction and different equilibrium point, hence this system is in neighbourhood stability, but in unstable equilibrium. An ecological analogy would be that the set of relative abundances of species (at Fig. 1i) can fluctuate within the limits of small perturbations (1), but should larger perturbations occur (2) then the system will move to a new configuration of relative abundances ( $\mathrm{B}$ or $\mathrm{C}$, Fig. 1 ).

i)

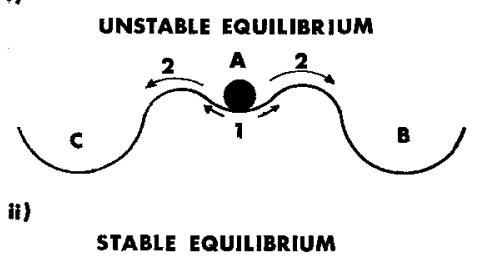

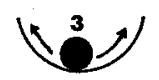

RELATIVE STABILITY

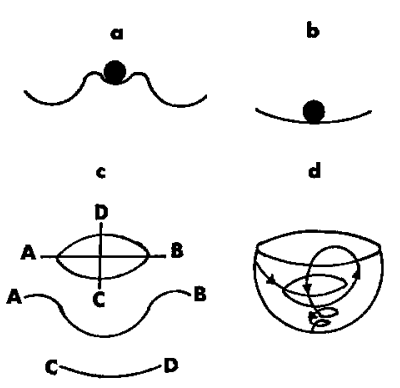

Fig. 1: Stability models. (I) The community is envisaged as a ball which will if perturbed by small amounts (scale 1) will return to the locally stable position A. Should the perturbation be greater (scale 2) then the system may move to other locally stable configurations B and C. $\mathrm{A}, \mathrm{B}$ and $\mathrm{C}$ are basins of attraction exhibiting neighbourhood stability. (II) In this model after large perturbations (scale 3 ) the system returns to a single stable point. Here the system exhibits neighbourhood and global stability

Fig. 2: Models of relative stability. (a) Unstable equilibrium, at an unlikely stable point. (b) System easily perturbed, taking a long time to reach equilibrium. (c) System more stable in plane of $A-B$ perturbation than in $C-D$ perturbation. (d) Oscillatory system which eventually reaches a stable equilibrium

If the perturbation is large ( 3 in Fig. 1ii) and the system returns to an equilibrium point from any point within the vector field then this system is in stable equilibrium and is in both neighbourhood and global stability. Only if there is no other basin of attraction within the vector field can a system be regarded as being in global stability. Global stability is therefore, as Lewontin (1969) points out, a negative condition, which may be trivially easy or impossibly difficult to test. In terms of the ecological analogy used above, here the set of relative abundances of species will return to the equilibrium set from large perturbations.

Whereas in physical systems stability analyses are based on neighbourhood or global models biological systems however, may be relatively stable or relatively unstable and the absolute criteria of neighbourhood and global stability do not help distinguish degrees of stability (Lewontin, 1969). Figure 2 illustrates four cases taken from Lewontin (1969). In Figure $2 a$ it is improbable that the system will be at the stable point shown since its basin of attraction is relatively small. Figure $2 \mathrm{~b}$ shows a system having a large basin of attraction and a slow progression to the stable point; such a system is easily perturbed. Figure $2 \mathrm{c}$ demonstrates a system which has great stability in relation to one plane of perturbation, (A-B), but little stability in relation 
to another perturbation, (C-D). Lastly, Figure $2 \mathrm{~d}$ shows an oscillatory system, where the system can behave erratically, and only over a long time period does it reach a stable point.

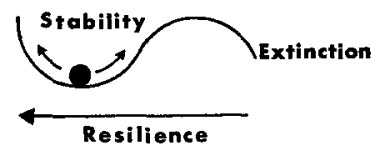

Fig. 3: Holling's models of ecological stability and resilience. Stability is the fluctuation around the equilibrium point. Resilence is the resistance to extinction

In ecological useage the word stability has had two different meanings. Stability has been used to mean either the ability of a system to return to an equilibrium state after a perturbation, or the persistence of a system through time. Holling (1973) has defined the "bounce-back" characteristics of a system as true stability and has called persistence through time the resilience of a system. Stability and resilience are not necessarily related since a system can be unstable and yet have high resilience and vice versa. The most widely used measurement of stability has been the fluctuations in abundances of populations around the equilibrium density (Fig. 3). Should the population fluctuate beyond certain limits then extinction occurs. Holling (1973) has suggested that the probability of extinction of a population could be used as a measure of resilience. Stability need not however, relate solely to fluctuations in numerical abundances of a population. Analyses of stability can be done on the stability of relative abundance patterns of species, the stability of species composition, or the stability of dominance (Krebs, 1972). Due to the inherent difficulties of sampling and the characteristics of the habitat itself, precise measurements of population fluctuations are not yet possible for the fauna of marine sediments and there is no information on the resilience of populations.

\section{PROBLEMS OF MEASURING THE STABILITY OF SEDIMENT ECOSYSTEMS}

With terrestrial habitats and marine intertidal or subtidal rocky habitats samples can be taken repeatedly from identical positions. Often exact in situ population counts can be made if the species under study are readily observable. With sedimentary habitats such analyses are not possible, sampling is blind and only statistical estimates of population densities for given areas can be made. In addition samples are taken by removing the substratum and so the sampling methods themselves will have a profound influence on the stability of the populations. Inevitably analyses of the stability of sediment-living populations therefore, will be less precise than on rocky substrates. An additional complicating factor affecting the stability of sediment-living benthos is the dynamic nature of the substratum. Disturbances due to increased wave and current activity or to the alteration of the grain-size composition by the animals may have profound influences on both the species and size of populations present. 
In order to simplify the arguments developed in this paper, I have taken examples where the sediment is relatively homogeneous over large areas (hundreds of $\mathrm{m}^{2}$ ) and remains homogeneous through time. This simplification does however, beg the question of how homogeneous an area must be and for what period of time to induce stability of the populations.

Most of the classical analyses of the stability of biological systems have been done on simple one-predator-one-prey systems. Marine benthic communities are characterised by large numbers of species from a diverse range of taxonomic groups. Analysis of stability along classical lines is as yet impossible. In this paper changes in dominance pattern are used to indicate structural changes in communities. I have used the simplest possible measurement of dominance, namely the percentage of the total population density or biomass contributed by a species. If the populations are stable then dominance should remain at a uniform level. It will be shown however, that most sediment-living communities show large changes in dominance, and benthic ecosystems may not be encompassed within the formal framework of stability analyses outlined above.

There are however, few extensive and/or long term sets of data that one can use for such analyses. I have taken a few examples from diverse papers and will support my conclusions with examples from other marine systems.

\section{Buzzard's B a y}

Sanders has done extensive sampling of the soft-bottom communities in Buzzard's Bay (Sanders, 1958, 1960). From an initial survey (1958) he selected a station, ( $R$ at $19 \mathrm{~m}$ depth) and studied population fluctuations from February 1956 to March 1957 (Sanders, 1960). Paired quantitative samples were taken with an anchor dredge at approximately monthly intervals. The sediment was composed of between 78.4 to

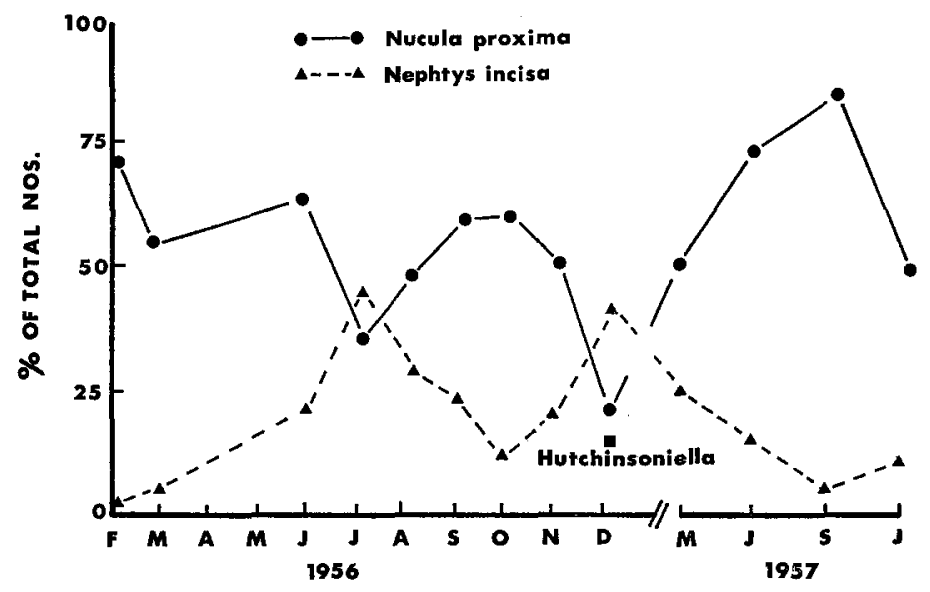

Fig. 4: Changes in dominance of infauna of an intertidal sand flat at Barnstaple Harbor, USA. (Data from Sanders, 1960) 
$90.3 \%$, silt-clay. Four samples were excluded from Sanders' detailed analyses ( 3 RA, $4 \mathrm{RB}, 6 \mathrm{RA}$ and $9 \mathrm{RA}$ ) since the silt-clay fraction fell below the above limits and in consequence the fauna was markedly different to the other samples. Plots of the mean percentage dominance for the above data are shown in Figure 4. Two species (the bivalve Nucula proxima and the polychaete Nephthys incisa) consistently dominated and contributed between 56 and $86 \%$ of the total numbers of animals. No other single species contributed over $10 \%$ in any month save for the cephalocarid Hutchinsoniella macracantba $11 \%$ in December 1956. Yet there were 96 species represented in this community.

Figure 4 shows that $N$. proxima and $N$. incisa had cyclical alterations in dominance, when $N$. proxima dominated; $N$. incisa was scarce and vice versa. The pattern in 1956 with two peaks of dominance by each species was not however, repeated in $1957, N$. proxima dominated throughout the year. Not all species in this community showed such dramatic oscillations in dominance, the polychaete Ninoe nigripes occurred consistently at around 5\% (1 to $9 \%$ range) and the bivalve Cylichna orzya at $5 \%$ (2 to $8 \%$ range).

\section{Scottish Sea Lochs}

One of the few detailed studies of benthos that has run for a number of years is that of Pearson $(1972,1973,1975)$, who has studied the benthic fauna of Lochs Eil and Linnhe, Argyllshire over a period of 11 years, from 1963-1973 inclusive. The study was a pre- and post-discharge investigation of the effects of organic material from a pulp and paper mill on the fauna. After initial surveys, six stations were studied five times per year from 1964-8 and twice per year from 1968-1973. The pulp mill effluent discharge started in March 1966. Data are presented here for two stations from spring surveys where five $0.1 \mathrm{~m}^{2}$ Van Veen samples of benthos were taken. The numbers and biomass of all species taken in the five grabs were used to calculate dominance values.

Table 1 shows data for Loch Linnhe and Loch Eil equidistant from the outfall, with the Loch Linnhe stations on the seaward side. The two stations had comparable grain size distributions (median diameter 3.1 for Loch Eil $3.3 ø$ for Loch Linnhe), although Pearson (1975) stated that the Loch Linnhe station was more variable in the amount of leaf litter input and sediment heterogeneity.

Prior to the discharge, dominance at both Lochs changed from year to year and was remarkably low for Loch Eil (maximum 22.6\%). After the perturbation caused by effluent discharge, beginning in 1966, the dominance pattern changed and annelids showed increased importance. Protodorvillea kefersteini became dominant in Loch Linnhe (except in 1970), but the second dominant varied among four other species (Table 1). At Loch Eil Capitella capitata assumed extreme dominance but the codominant species alternated between five other species (Table 1).

Assessment of numerical dominance may not be of ecological importance if the dominant species is of small size and biomass. Table 2 shows dominance patterns by biomass of each species for the same Loch Linnhe and Eil data. Biomass dominance at Loch Linnhe oscillated between the bivalve (Myrtea spinifera) in 1963 to Ecbinocar- 


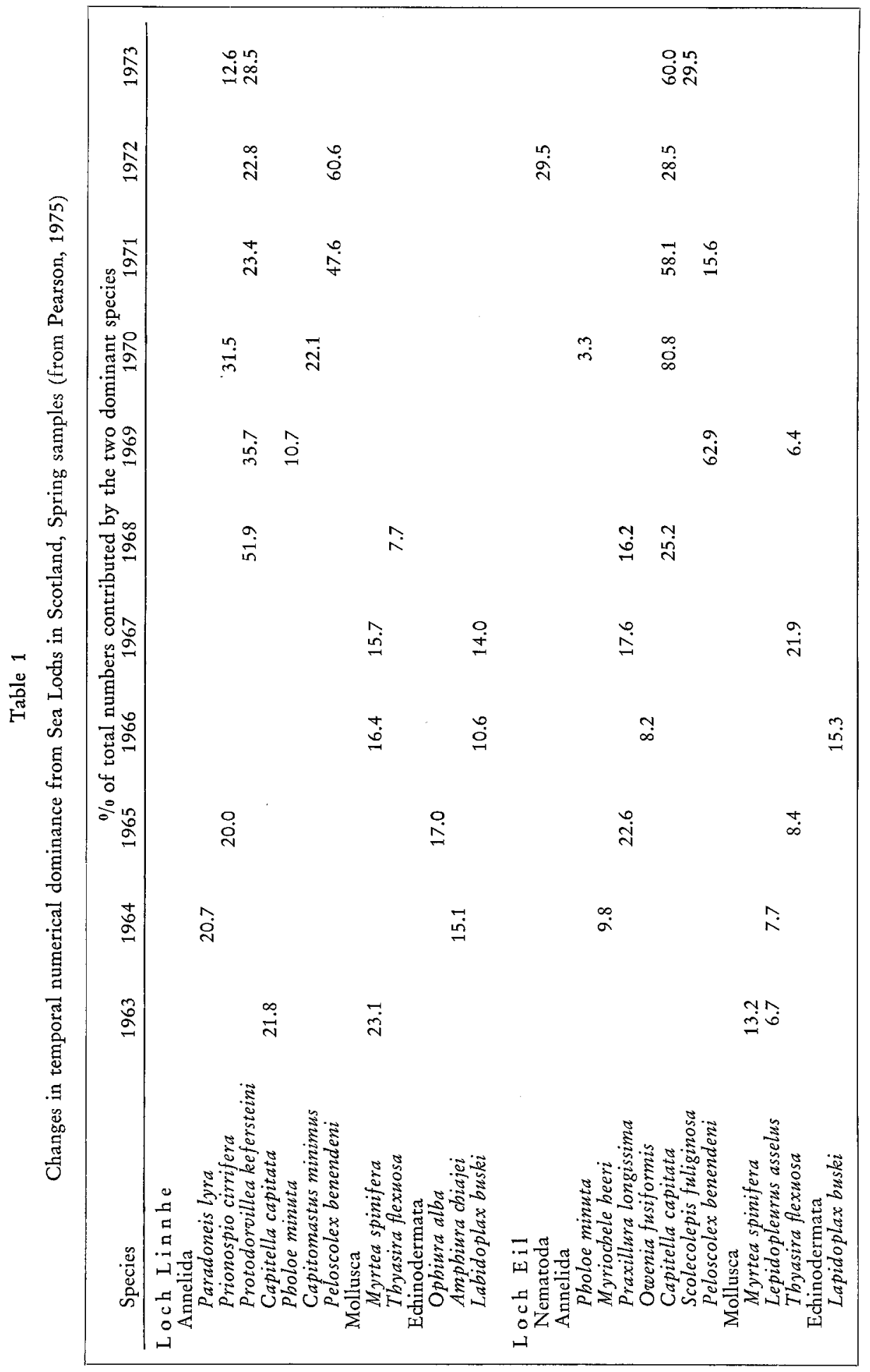


Stability of benthic ecosystems

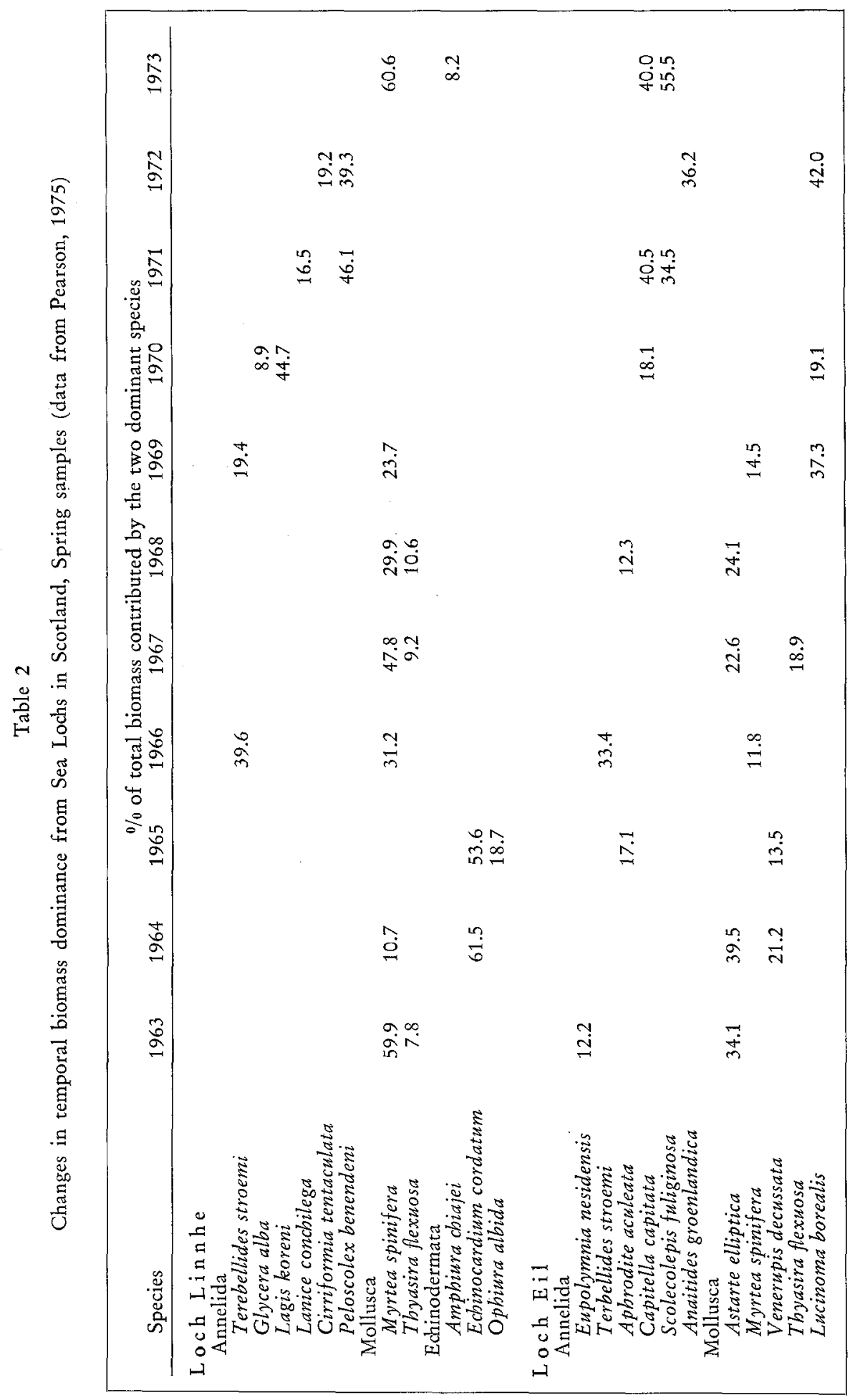


dium cordatum in 1964 and 1965, to the annelid Terebellides stroemi in 1966 and back to $M$. spinifera 1967, 1968 and 1969, three years after effluent discharge commenced. From 1969 the dominant species switched to the polychaete Lagis koreni 1970, the oligochaete Peloscolex benendeni in 1971 and 1972 an back to M. spinifera in 1973. Only with M. spinifera in 1967 and $P$. benendeni in 1971 and 1972 did numerical and biomass dominance coincide.

In Loch Eil biomass dominance was as variable, switching from the bivalve Astarte eliptica in 1963 and 1964, to the polychaetes Apbrodite aculeata in 1965 and Terebellides stroemi in 1966, back to Astarte in 1967 and 1968 and to another bivalve Lucinoma borealis in 1969 and 1970 then to the polychaete Capitella capitata in 1971, L. borealis in 1972 and Scolecolepis fulinginosa in 1973. Only in 1971 with Capitella capitata did numerical and biomass dominance coincide.

Clearly from both Sander's and Pearson's data for the fauna of homogeneous sediments dominance switched from species to species. The mechanisms producing such changes in dominance were not investigated since in the examples given, the detailed historical development of the sites was not or could not be tollowed.

Changes in dominance can be produced by changes in the physical environment, by competition between species, by predation on certain species, by differential larval settlement and by the activities of the animals themselves rendering the sediment unsuitable for their own or other species. Changes in dominance due to variation of the physical environment brought about by storms, severe winters etc. will not be considered in this paper, but are well documented. Instead the neglected but important role of biological interactions will be considered.

\section{DOMINANCE CHANGES DUE TO BIOLOGICAL INTERACTIONS}

The classical demonstration of the importance of biological interaction between species in marine sediment habitats is that of Segerstrale on Macoma balthica in the Baltic Sea. Segerstråle (1973) has studied the numerical abundance of $M$. balthica at a station (No. 26) off Tvärminne since 1926. In some years densities have approached $1785 \mathrm{~m}^{-2}$, but in the 1960's densities were down to $20 \mathrm{~m}^{-2}$. In the latter period the amphipod Pontoporeia affinis dominated with densities of up to $986 \mathrm{~m}^{-2}$.

Two adjacent stations (Spar Buoy West F and Spar Buoy East B) at $20 \mathrm{~m}$ depth sampled intensively from 1960-63 show the dynamic relationship between $M$. balthica and $P$. affinis (Fig. 5). At Spar Buoy West F P. affinis dominated but at Spar Buoy East B $M$. balthica dominated. Yet both sites are equally suitable for both species. Should $P$. affinis decline in numbers then $M$. baltbica will recruit successfully. Segerstråle's studies (1969) have shown that $P$. affinis utilises sediment as its food resource and destroys settling $M$. baltbica. Recruitment failure of $M$. baltbica at some sites where $P$. affinis abounds has been recorded for periods of up to 25 years. The interaction between $M$. balthica and $P$. affinis is not strictly predatory and is better termed interference competition, which results in a dynamic spatial and temporal balance between the two species, although the time scale of the oscillations is not predictable.

A similar interaction has been clearly demonstrated by Mills (1969) for an inter- 
tidal sand-flat in Barnstable Harbor, Massachusetts (Fig. 6). In 1959 that flat was dominated by the gastropod Nassarius obsoletus, which disturbed the sediment by its activity and so kept the number of coexisting species low. In fall 1960 or spring 1961 a breeding population of the amphipod Ampelisca abdita became established. It reproduced rapidly and in forming a dense mat of tubes out-competed $N$. obsoletus for available space. $A$. abdita by its feeding put small particles into suspension which therefore, changed the sediment median grain size. The mat of tubes became unstable and $A$. abdita was washed out by wave action in September to October, allowing $N$. obsoletus to re-establish on the flat. Again, like Macoma baltbica and Pontoporeia affinis two species exist in a temporally dynamic equilibrium.

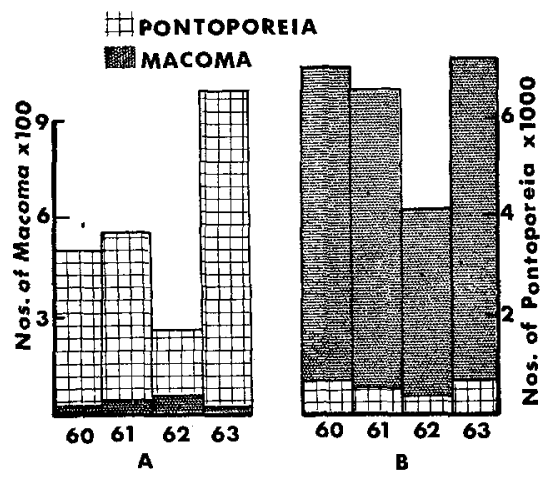

Fig. 5: Abundance patterns of Potoporeia and Macoma at two stations in the Baltic Sea, A) Spar Buoy West F station, B) Spar Buoy East B station. (Data from Segerstråle, 1973)

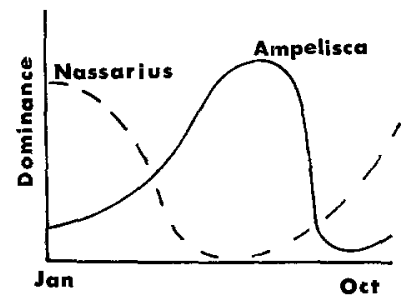

Fig. 6: Changes in dominance patterns giving dynamic stability, in fauna of a mudflat at Barnstaple Harbor, USA. (Data from Mills, 1969)

Not all systems where an organism alters the sediment grain size distribution lead to alternating dominance patterns. Rhoads and Young $(1970,1971)$ working in Cape Cod showed that the holothurian Molpadia oolitica by constantly re-working the sediment excluded many suspension feeding species and yet allowed a few species to co-exist on faecal cones. $M$. oolitica occurs in large numbers over wide spatial areas and has persisted for many years. Here the community can be extremely stable.

A similar example of the extreme stability of a benthic population produced by biological interaction can be found in studies on Calocaris macandrae (Buchanan, 1974). Off the Northumberland coast C. macandrae has been found at densities of 
$17.95 \mathrm{~m}^{-2}$ with a coefficient of variation of only $5.4 \%$, for a period of 10 years. C. macandrae is highly territorial and presumably if an individual dies it is rapidly replaced giving an extremely stable population.

One of the most successful ways of assessing the importance of biological interactions in affecting the stability of the fauna in sedimentary habitats is by manipulation of the populations. Woodin (1974) put cages over an intertidal mudflat in Washington, USA in order to exclude predators and prevent settlement of some species. Table 3 shows the results after a period of 4 months. The dominant species, a tube-

Table 3

Changes in dominance in the fauna of an intertidal mudflat in Washington State, USA, caused by excluding the larvae of tube-building polychaetes by the use of cages for a 4 month period. (Data from Woodin, 1974)

\begin{tabular}{|ccc|}
\hline $\begin{array}{c}\text { Experimental } \\
\text { condition }\end{array}$ & $\begin{array}{c}\text { Tube dweller } \\
\text { (Platynereis bicaniculata) }\end{array}$ & $\begin{array}{c}\text { Burrower } \\
\text { (Armandia brevis) }\end{array}$ \\
\hline No cage & 51.17 & 7.60 \\
Cage & 8.62 & 33.40 \\
\hline
\end{tabular}

dwelling polychaete Platynereis bicaniculata reproduced during the 4 month period and larvae were unable to reach the sediment surface, but instead settled on the cage surfaces. Larvae of the burrowing polychaete Armandia brevis burrowed through the meshes of the cages, reached the mud surface and therefore, increased in abundance. Woodin concluded that these two species compete for space; normally A. brevis is outcompeted and maintains a low abundance.

In addition to the clear evidence of competition for space, Woodin was also able to show that predators can have a dramatic effect on altering dominance patterns in the sediment. One small specimen of the crab Cancer magister was added to a cage

Table 4

Changes in dominance in the fauna of an intertidal mudflat in Washington State, USA, caused by adding a predator (Cancer magister) to a cage for a period of 4 months.

(Data from Woodin, 1974)

\begin{tabular}{|ccc|}
\hline Predator & \multicolumn{3}{c|}{$\begin{array}{c}\text { Tube dweller } \\
\text { (Leptochelia savignyi) }\end{array}$} & $\begin{array}{c}\text { Burrower } \\
\text { (Armandia brevis) }\end{array}$ \\
\hline No Cancer magister & 67.40 & 3.93 \\
With Cancer magister & 25.52 & 25.75 \\
\hline
\end{tabular}

for a period of 4 months (Table 4). Whereas the numbers of $A$. brevis increased (3.93 to $35.75 \%$ ) the numbers of 5 tube-dwelling species fell markedly; the normally dominant tanaid Leptochelia savignyi fell dramatically in abundance, $(67.40 \%$ to $25.52 \%$.) The effects of predators may therefore, cause marked alterations in dominance and such effects may be highly localised. 
The importance of the spatial variation in larval recruitment was demonstrated in another series of cages kept in situ for 6 months (Table 5). Whereas tube dwellers dominated $(96.34 \%$ ) in control areas, the burrowing species Armandia brevis dominated $(53.44 \%)$ in areas where larval recruitment was high. The inverse correlation

Table 5

Changes in dominance in the fauna of an intertidal mudflat in Washington State, USA, caused by spatial variations in larval recruitment within a series of cages placed in situ for 6 months. (Data from Woodin, 1974)

\begin{tabular}{|ccc|}
\hline $\begin{array}{c}\text { Experimental } \\
\text { condition }\end{array}$ & $\begin{array}{c}\text { Tube dwellers } \\
(3 \text { species })\end{array}$ & $\begin{array}{c}\text { Burrowers } \\
\text { (Armandia brevis) }\end{array}$ \\
\hline No cage & 91.34 & 8.65 \\
Cage & 86.34 & 13.57 \\
& 85.41 & 14.59 \\
& 84.65 & 15.35 \\
& 64.90 & 35.10 \\
& 46.65 & 53.44 \\
\hline
\end{tabular}

between abundance of tube-dwellers and abundance of the burrower, $A$. brevis, thus confirmed the finding above that space is a limiting resource for which competition is intense. Variability in the degree of dominance, however, was produced by variations in abundance of larval settlement.

Field manipulation of populations does not, however, always lead to such dramatic changes in dominance. The intertidal mud-flats of the river Tees estuary, England, are dominated by annelids (oligochaetes and polychaetes) with densities in excess of $2 \times 10^{5} \mathrm{~m}^{-2}$. The mud-flats cover $5 \mathrm{~km}^{2}$ and in winter support a large population of over-wintering birds, including shelduck (Tadorna tadorna, 2000 at peak count), Knot (Calidris canutus 10,000 park count), Dunlin (Calidris alpina 10-15,000 at peak count) with Bar-tailed Godwit (Limosa limosa) and the Redshank (Tringa totanus) at 500 peak count. The macrofauna of the estuary is sparse (Gray, 1976) and the birds feed largely on the small oligochaetes and polychaetes. Predation pressure in the winter is, therefore, great. Cages covering $2 \times 2 \mathrm{~m}$ were erected at two sites to exclude predators from October 1975 through to June 1976. Paired samples of the fauna were taken by core from within the cage and from a control area outside the cage at monthly intervals. Figure 7 shows the changes in dominance for the common species at the two sites. At both sites the gastropod Hydrobia ulvae has increased in numerical dominance up to $7 \%$. The other species show little change in dominance patterns suggesting that the $H$. ulvae is not competing with the annelids for space or food. Newell (1965) has shown that $H$. ulvae feeds on the surface, utilising its own faeces which have been enriched by bacterial action. It is unlikely therefore, to compete with the annelids. Since $H$. ulvae is larger than the annelids, biomass dominance has risen more dramatically than numerical dominance. The lack of predator impact on the fauna can be explained by the fact that Manayunkia aestuarina is not used as food. The commonest food item, the oligochaete Peloscolex benendeni, is long and thin and is 
broken easily if pulled from the sediment, but can rapidly regenerate. Numerical abundance patterns remain closely similar. Gray (1976) has shown that the mean biomass in the winter is half that of the summer; the reduction in biomass probably being due to seasonal mortality and predation. We cannot however, be certain that

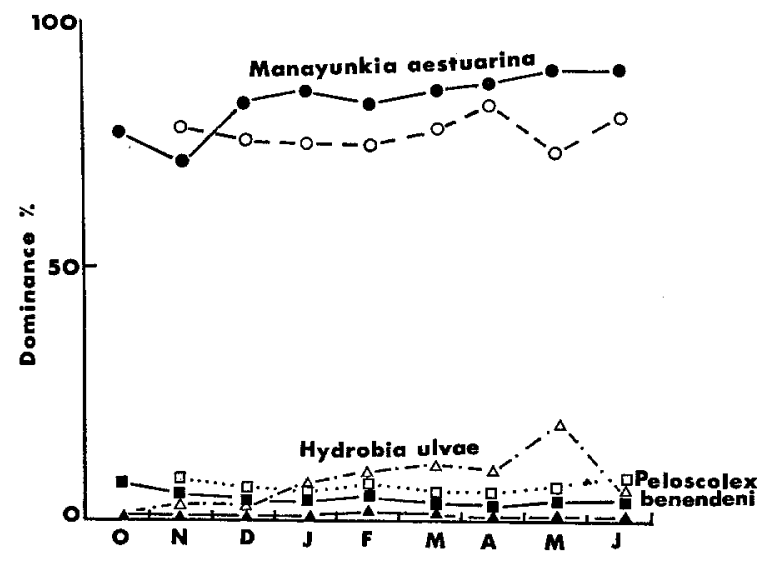

Fig. 7: Dominance patterns in caged (open symbols) and uncaged (closed symbols) sites in a mudflat in the river Tees estuary (England)

a
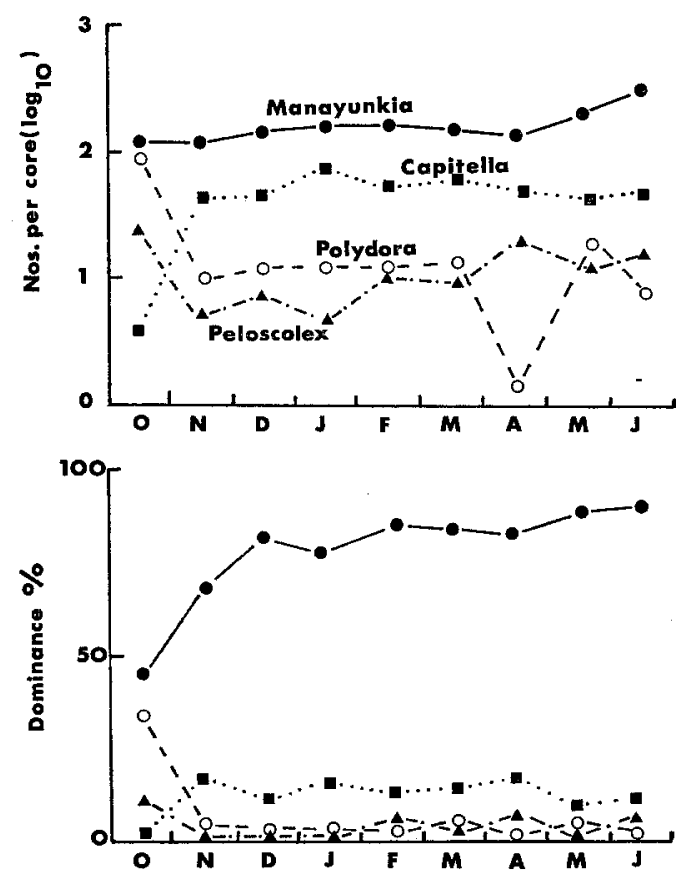

Fig. 8: Abundance (a) dominance, (b) patterns, of the fauna of a mudflat in the river Tees estuary (England) after clearance of surface mud in October 1975 
all small Carcinus maenas were excluded from the cages and these results may only reflect predation by Carcinus maenas.

In another series of experiments in the Tees estuary, surface mud was removed from two sites in October 1965. Figure 8 shows the data for one of the sites. The numbers of Manayukia aestuarina remained constant, whilst those of Polydora ciliata and Peloscolex benendeni declined and these species were replaced by Capitella capitata. The dominance of Manayunkia aestuarina increased even though this species did not increase in abundance. Prior ot the clearance of surface mud, the sites were dominated by tubes of Polydora ciliata which had densities of over $200,000 \mathrm{~m}^{-2}$. Whereas $M$. aestuarina, $P$. benendeni and C. capitata reproduce throughout the winter, $P$. ciliata reproduces in the spring. The lack of major recruitment of $P$. benendeni was probably due to predation by birds. C. capitata, in the absence of $P$. ciliata increased both in abundance and dominance. Such changes may be the result of less competition for space. Since $P$. ciliata occupied much of the available space prior to removal of the surface mud, a greater increase in numbers of potential competitors was expected. It does not appear therefore, that competition for space is as intense in the Tees as was the case in Woodin's study area. A more detailed account of the above experiments will be published elsewhere.
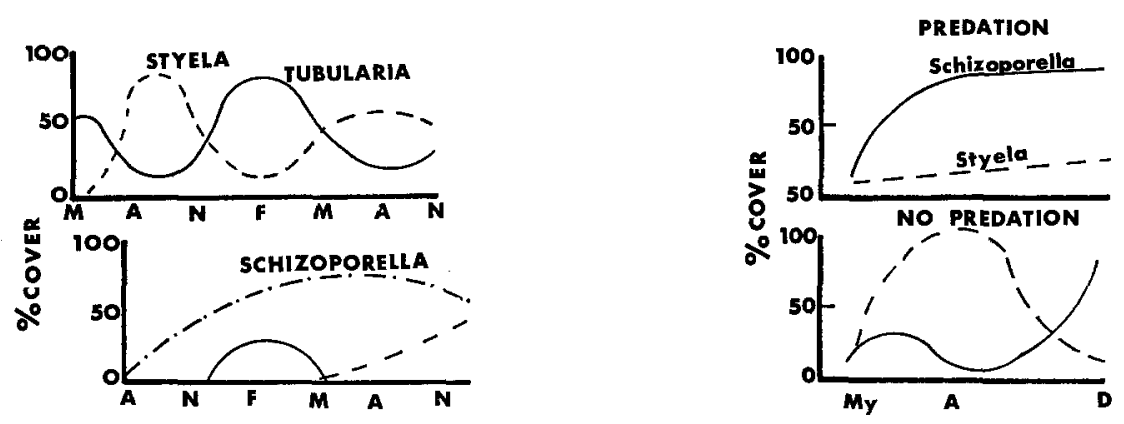

Fig. 9: Changes in $\%$ cover of organisms on ceramic tiles submerged at Beaufort, N.Carolina, USA, showing two series of experiments. (Data from Sutherland, 1974)

Fig. 10: Changes in \% cover of organisms on ceramic tiles within cages (no predation) compared with controls (predation). (Data from Sutherland, 1974)

In an elegant series of experiments, Sutherland (1975) followed the development of a fouling community on ceramic tiles placed on a floating dock at Beaufort, $\mathrm{N}$. Carolina. The set of tiles placed out in May 1971 were initially dominated by the hydroid Tubularia croaca (Fig. 9). In June the tunicate Styela plicata settled underneath the Tubularia canopy and developed into a single species stand. In November S. plicata died and the S. plicata mat sloughed off allowing Tubularia creaca to return. Plates submerged in August however, became dominated by the bryozoan Schizoperella unicornis which persisted for over a year (Fig. 9).

In a further series of experiments Sutherland excluded predatory fish by enclosing plates within cages (Fig. 10). The control cages showed a typical pattern with dominance by $S$. unicornis. Inside the cages with no predation, Styela plicata formed 
a mono-culture, which was replaced by $S$. unicornis when $S$. plicata died in the autumn. Fish predators, therefore, usually remove young $S$. plicata and prevent the development of this species.

Further experiments repeating the above experiments in subsequent years did not lead to the same results. Larval recruitment varied from year to year, which together with the variability in fish predation gave, as yet, unpredictable changes in dominance.

\section{MULTIPLE STABLE POINTS}

Based on the above experiments, Sutherland has suggested that the dominance by Styela plicata or Schizoporella unicornis represented two alternative stable points for the fouling community. Which of the two species dominated depended on the time at which space was available for colonisation by larvae and whether or not predation occurred.

\section{MULTIPLE STABLE POINTS}

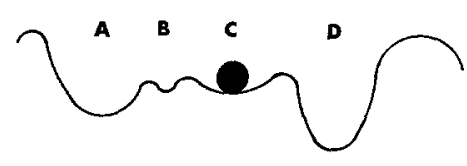

SPACE OR TIME

Fig. 11: Model of the stability of benthic communities in a spatial or temporal series. Here the community is envisaged as the ball which can oscillate between four potentially dominant species $\mathrm{A}, \mathrm{B}, \mathrm{C}$ and $\mathrm{D}$. For a detailed explanation see text

For sediment communities, Sander's data for Buzzard's Bay showed that dominance alternated between Nucula proxima and Nephtbys incisa, but like the fouling community the pattern varied from year to year. Pearson's longer term study in Scottish sea lochs showed a more variable pattern of dominance even before the perturbation of the community caused by the input of organic matter. Dominance, which was never large (maximum $23.1 \%$ ) oscillated between 3 species. After input of organic matter dominance became more extreme (up to $80.8 \%$ ), and alternated between two species at both lochs.

A graphical representation of the stability of benthic sediment communities can be represented by Figure 11 . The system has four potentially dominant species, A, B, C, and $D$. The community is shown dominated by species $C$. If perturbed however, the system (the ball) may switch to dominance by species B or D. Whereas B is relatively unstable and is likely to be easily perturbed to dominance by A or C, D is a highly stable configuration and the system is likely to persist with this species dominating. Taking Pearson's Loch Linnhe data as an example (Table $1 \& 2$ ), initially the bivalve Myrtea spinifera dominates in 1963 (position C). This switches to the annelid Para- 
doneis lyra in 1964 (B), a more stable Prionospio cirrifera dominance (A) in 1965 and back to Myrtea (C) in 1966 and 1967. Perturbation by organic matter, switches the system to a very stable dominance by Protodorvillea kefersteini (D) from 1968 to 1973.

A structural model based on the existence of multiple stable points does seem to be a realistic interpretation of the stability of most, but not necessarily all benthic communities. Sutherland (1974) gives examples of the existence of multiple stable points in the rocky intertidal, on coral reefs and in freshwater lakes. Multiple stable points have recently been demonstrated in a New Hampshire forest, where three co-occuring tree species beech, maple and birch were alternative dominants, (Forcier, 1975). The reproductive strategies and growth rates of the trees were used to explain an "ecological carousel", of alternating stable points.

The concept of multiple-stable points is not new in ecology. For many years a major controversy centred on the theories of community development. Clements (1916) and Tansley (1920) believed that communities through time grew, matured and developed into a climax state dominated by one or a few species. If the community died it would be replaced by an identical climax. The Clements-Tansley view of community development is therefore, of a globally stable system.

The idea of a single climax has been replaced and by the poly-climax theory, (Gleason, 1926), which has found general acceptance by botanists and zoologists. This theory states that in a continuously varying environment the vegetation varies continuously and no two associations are identical, and thus alternative climax states occur. The existence of multiple stable points and neighbourhood stability are clearly logical extensions of the poly-climax to a dynamic view of community development.

One of the central controversies arising from the opposing views of community development concerned the classification of communities. The Clements-Tansley view of a single fixed climax implied that clearly defined communities could be defined and classified. In Gleason's poly-climax, since no two associations were identical the associations could not be classified or easily defined. Yet marine ecology has for many years been involved solely in classifying and designating communities (e.g. Petersen, 1915; Thorson, 1957; Jones, 1950). It is my belief that sediment communities typically have multiple stable points and show neighbourhood stability and so correspond to the poly-climax theory of community development. A consequence of the existence of multiple stable-points is that communities will be difficult to classify as has indeed proved to be the case on many occasions.

Not all communities show multiple stable points and neighbourhood stability. The fauna of Cape Cod Bay was shown to be dominated by the holothurian Molpadia oolitica and Calocaris macandrae has been stable for over ten years off the Northumberland coast. In such communities global stability appears to be a realistic model. One of the essential goals of research on the temporal dynamics of benthic communities should be therefore, perturbation experiments designed to test for the existence of multiple or single stable points in the system.

Recently Mills (1975) has criticised, rightly in my opinion, the work of benthic ecologists, which he states is: "A rather shabby and intellectually suspect branch of biological oceanography. Its methods are, for the most part, those of the nineteenth 
century; its results, too often, are of interest only to other students of the benthos; and its importance to other branches of biological oceanography has been proportionately small." He asks benthic ecologists "to avoid the fruitless or irrelevant activities of the past, to get meaningful results both in terms of ecological theory and practical application."

Knowledge of the appropriate model for the stability of benthic communities can help pose more meaningful questions concerning the description of communities and the fluctuations in abundance of species. Clearly ecologists must consider the causes of instability of both populations and communities. From the studies of Segerstråle (1973) on competition and interference, Woodin (1974) on competition and predation we know that biological interactions are highly important in determining the structure of some but not all benthic communities. Mills' (1969) study on Ampelisca abdita however, shows that sediment-living communities have an extra complication compared with rocky shores; in sediments the animals can alter their own environment which may lead to alternating stability as with Ampelisca abdita and Nassarius obsoletus or to a highly stable system as with Molpadia oolitica (Rhoads \& Young, 1971). The causal factors leading to changes in dominance need to be thoroughly understood if ecologists are to be expected to produce reliable models of benthic communities. Inevitably to acquire this knowledge will mean a return to studies of natural history. Once information is available on competition, predation, recruitment etc. then simple structural models such as Markov chains can be used. In terms of Markov chains, the community can be envisaged as having a number of potential states (the dominant species). A switch in dominance from species to species is referred to as the transition from state to state. A Markov chain is characterised by the probabilities that the system moves from any state to any state on successive occasions (Grossman \& Turner, 1974). The probabilities of changes in dominance can be established by observation of communities and by perturbation experiments. Not all communities however can be modelled by Markov chains. In some communities once a certain species dominates then the community remains with that species dominating (e.g. Molpadia oolitica). In such cases absorbing Markov chain models are appropriate. In conclusion therefore, whereas Markov chain models can be used in systems in neighbourhood stability, having multiple stable points, absorbing Markov chains are models for globally stable systems.

The existence of multiple stable points in benthic communities probably results from the fact that effects of perturbations of the system (competition, predation interference, re-working etc.) are non-linear and the total species complement of the communities fluctuates (Lewontin, 1969). Yet most systems theory models of communities utilize linear equations which have a single stable point, largely due to the tractability of such analyses and to the fact that on a macro-scale communities behave linearly (Patten, 1975). Such models will give poor predictions of systems where multiple stable points occur (Sutherland, 1976); yet analyses of non-linear systems are extremely complex (Holling, 1973).

Theoretical aspects of ecology have scarcely been applied to the study of benthic communities. Most of benthic "ecology" has sought relationships between the physical properties of the environment and species distribution, ideas which were modified 
over twenty years ago in terrestrial ecology by appreciation of the importance of biological interactions. Studies of niche proportions, competition, predation and interference (which includes re-working of sediments), all of which have a well developed theoretical side, have been badly neglected. If we are to understand the dynamics of benthic communities with a view to modelling temporal changes, much more information is needed on the biological interactions between species.

\section{LITERATURE CITED}

Buchanan, J. B., 1974. A study of long term stability in a benthic crustacean. Proc. Challenger Soc. 4, 252-253.

Clements, F. E., 1916. Plant succession. An analysis of the development of vegetation. Publs Carnegie Instn 242, 512 pp.

Forcier, L. K., 1975. Reproductive strategies and the co-occurrence of climax tree species. Science, N.Y. 189, 808-810.

Gleason, H. A., 1926. The individualistic concept of the plant association. Bull. Torrey bot. Club 53, 7-26.

Gray, J. S., 1976. The fauna of the polluted river Tees estuary. Estuar. coast. mar. Sci. (In press).

Holling, C. S., 1973. Resilience and stability of ecological systems. A. Rev. Ecol. Syst. 4, 1-23.

Jones, N. S., 1950. Marine bottom communities. Biol. Rev. 25, 283-313.

Krebs, C. J., 1972. Ecology. Harper \& Row, New York, 694 pp.

Lewontin, R. C., 1969. The meaning of stability. Brookhaven Symp. Biol. 22, 13-24.

May, R. M., 1973. Stability and complexity in model ecosystems. Princeton Univ. Press, New Jersey, $235 \mathrm{pp}$.

Mills, E. L., 1969. The community concept in marine zoology, with comments on continua and instability in some matine communities: a review. J. Fish. Res. Bd Can. 26, 1415-1428.

- 1975. Benthic organisms and the structure of marine ecosystems. J. Fish. Res. Bd Can. 32, $1657-1663$.

Newell, R. C., 1965. The role of detritus in the nutrition of two deposit feeders the prosobranch Hydrobia ulvae and the bivalve Macoma baltbica. Proc. zool. Soc. Lond. 144, 25-45.

Patten, B. C., 1975. Ecosystem linearization. An evolutionary design problem. In: Ecosystem analysis and prediction. Ed. by S. A. Levin. Soc. ind. appl. math., Philadelphia. 168-201.

Pearson, T. H., 1970. The benthic ecology of Loch Linnhe and Loch Eil, a sea-loch system on the west coast of Scotland. I. The physical environment and the distribution of the macrobenthic fauna. J. exp. mar. Biol. Ecol. 5, 1-34.

- 1971. The benthic ecology of Loch Linnhe and Loch Eil, a sea-loch system on the west coast of Scotland. III. The effect on the benthic fauna of the introduction of pulp mill effluent. J. exp. mar. Biol. Ecol. 6, 211-233.

- 1975. The benthic ecology of Loch Linnhe and Loch Eil, a sea-loch system on the west coast of Scotland. IV. Changes in the benthic fauna attributable to organic enrichment. J. exp. mar. Biol. Ecol. 20, 1-41.

Petersen, C. G. J., 1915. On the animal communities of the sea bottom in the Skagerak, the Christiana Fjord and the Danish waters. Rep. Dan. biol. Stn. 23, 3-28.

Rhoads, D. C. \& Young, D. K., 1970. The influence of deposit-feeding benthos on bottom sediment stability and community trophic structure. J. mar. Res. 28, 150-178.

- - 1971. Animal-sediment relations in Cape Cod Bay, Massachusetts. II. Reworking by Molpadia oolitica (Holothuroidea). Mar. Biol. 11, 255-261.

Sanders, H. L., 1958. Benthic studies in Buzzard's Bay. I. Animal-sediment relationships. Limnol. Oceanogr. 3, 245-258. 
- 1960. Benthic studies in Buzzard's Bay. III. Structure of the soft-bottom community. Limnol. Oceanogr. 4, 138-153.

Segerstråle, S. G., 1973. Results of bottom sampling in certain localities in the Tvärminne area (inner Baltic), with special reference to the Macoma-Pontoporeia theory. Commentat. biol. 67, 3-12.

Sutherland, J. P., 1974. Multiple stable points in natural communities. Am. Nat. 108, 859-873.

Tansley, A. G., 1920. The classification of vegetation and the concept of development. J. Ecol. 8, 118-149.

Thorson, G., 1957. Bottom communities (sublittoral or shallow shelf). In: Treatise on marine ecology and paleoecology. Ed. by J. W. Hedgpeth. Geol. Soc. Am., New York, 1, 461-534. (Mem. geol. Soc. Am. 67.)

Woodin, S.A., 1974. Polychaete abundance patterns in a marine soft-sediment environment. The importance of biological interactions. Ecol. Monogr. 44, 171-187.

Author's address: Dr. J. S. Gray

Universitetet i Oslo

Institutt for Marinbiologi og Limnologi

Postboks 1064

Blindern, Oslo

Norway 